\title{
Sífilis secundaria: reporte de 2 casos
}

Secondary syphilis: 2 cases' report

\author{
Yaisa Valeria Diaz Cuero', Andrés Vidal Cagigas² \\ 1. Médica, residente de segundo año Dermatología Universidad ICESI-FVL, Cali, Colombia. \\ 2. Médico Dermatólogo, Docente Universidad ICESI-FVL, Cali, Colombia.
}

\section{RESUMEN}

La sífilis es un enfermedad de transmisión sexual (ETS), causada por la bacteria espiroqueta Treponema pallidum subespecie pallidum, la sífilis secundaria es una etapa caracterizada por hallazgos clínicos variados, incluyendo una amplia variedad de manifestaciones cutáneas que típicamente aparecen a las 4-10 semanas de la infección inicial. Dentro de las manifestaciones clínicas más frecuentes de la sífilis secundaria se encuentra el típico exantema palmar y plantar que es la manifestación dermatológica más común. Se describen 2 casos con manifestaciones en palmas y plantas.

PALABRAS CLAVE: sífilis secundaria, exantema palmar, Treponema pallidum

\section{SUMMARY}

Syphilis is a sexually transmitted disease (STD) caused by the bacterium spirochetes Treponema pallidum subspecies pallidum, secondary syphilis is a stage characterized by variety of clinical findings, including a wide variety of dermal manifestations appearing typically 4-10 weeks after the initial infection. The typical palmar and plantar exanthema is the most common dermal manifestation. We describe 2 cases with manifestations in palms and soles.

KEY WORDS: secondary syphilis, palmar exanthem, Treponema pallidum

\section{CASO CLÍNICO No 1}

Paciente masculino de 23 años de edad, originario y procedente de Cali, con cuadro clínico de un mes de aparición de lesiones descamativas y pruriginosas en arcos plantares, de posterior aparición en palmas en donde le han dejado pigmentaciones, y un brote papular fino en abdomen que duro unos pocos días. Consulto a su entidad de salud, donde le hicieron $\mathrm{KOH}$ de estas lesiones con resultado negativo y VIH negativo.

$\mathrm{Al}$ examen físico fototipo de piel IV, en palmas y plantas placas pequeñas pigmentadas con hiperqueratosis y algunas con un collarete central descamativo (figura 1).

\author{
Correspondencia: \\ Yaisa Valeria Diaz Cuero \\ Email: \\ yaisadiaz@gmail.com \\ Recibido: 29/06/18 \\ Aceptado: 06/11/18
}

Conflictos de interés:

No se reportan conflictos de interés.

Financiación:

Ninguna. 
Se hace sospecha diagnostica de sífilis secundaria y se le solicita hemograma, RPR.

Resultado de RPR: reactiva 128 diluciones, con prueba FTA-abs positivo, se prescribe tratamiento con penicilina benzatinica 2.400.00o UI IM en el momento y en 7 días y se solicita valoración y seguimiento por Infectología.

\section{CASO CLIINICO N 2}

Paciente masculino de 25 años de edad, originario de Buenaventura, procedente de Cali, con cuadro clínico de un año de evolución de aparición de lesiones perianales, que interpretó como condilomas, se había automedicado con imiquimod y podofilina con lo que las controlaba, pero vuelven a aparecer, también consulta por aparición de placas descamativas en plantas y palmas de 1 año de evolución.

$\mathrm{Al}$ examen físico se observa una dermatitis irritativa aguda severa, exudativa, en zona perianal e interglútea e irritación en escroto con dolor al caminar y sentarse. También se observan placas en palmas y plantas con collaretes descamativos (figura 2).

Con exámenes de laboratorio: Serología RPR: positiva 128 diluciones, FTA-abs positivo

Se prescribe tratamiento con penicilina benzatinica 2.400.00o UI IM en ese momento y en 1 semana, valoración y seguimiento por Infectología, valoración por coloproctología para rectoscopia por historia de condilomas perianales.

\section{DISCUSIÓN}

La sífilis es un enfermedad de transmisión sexual (ETS), causada por la bacteria espiroqueta Treponema pallidum subespecie pallidum ${ }^{(1)}$, acorde con el más reciente estimado de la Organización Mundial de la Salud (OMS), aproximadamente 5.6 millones de nuevos casos de sífilis ocurren anualmente en el mundo. ${ }^{(2)}$

La infección comienza cuando la bacteria hace contacto con la piel o con la mucosa, multiplicándose localmente por varios días, mientras simultáneamente se disemina por los vasos sanguíneos y linfáticos.

La aparición de una ulcera indolora, más conocido

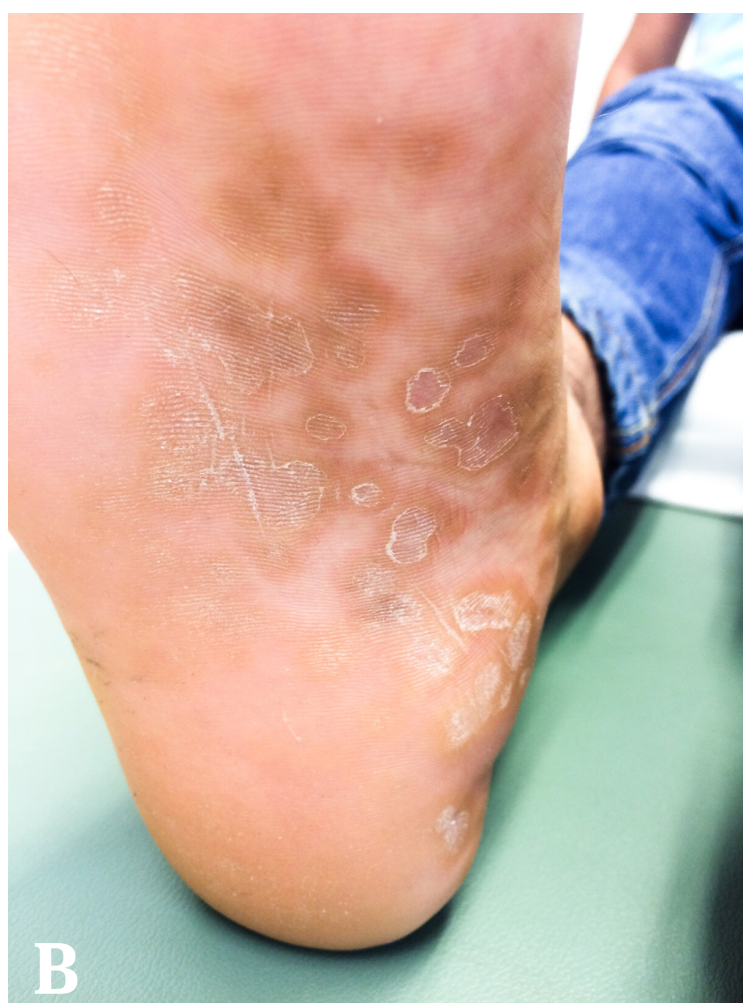

Figura 1. A y B) Placas pigmentadas con hiperqueratosis y con collarete central descamativo en palmas y plantas 

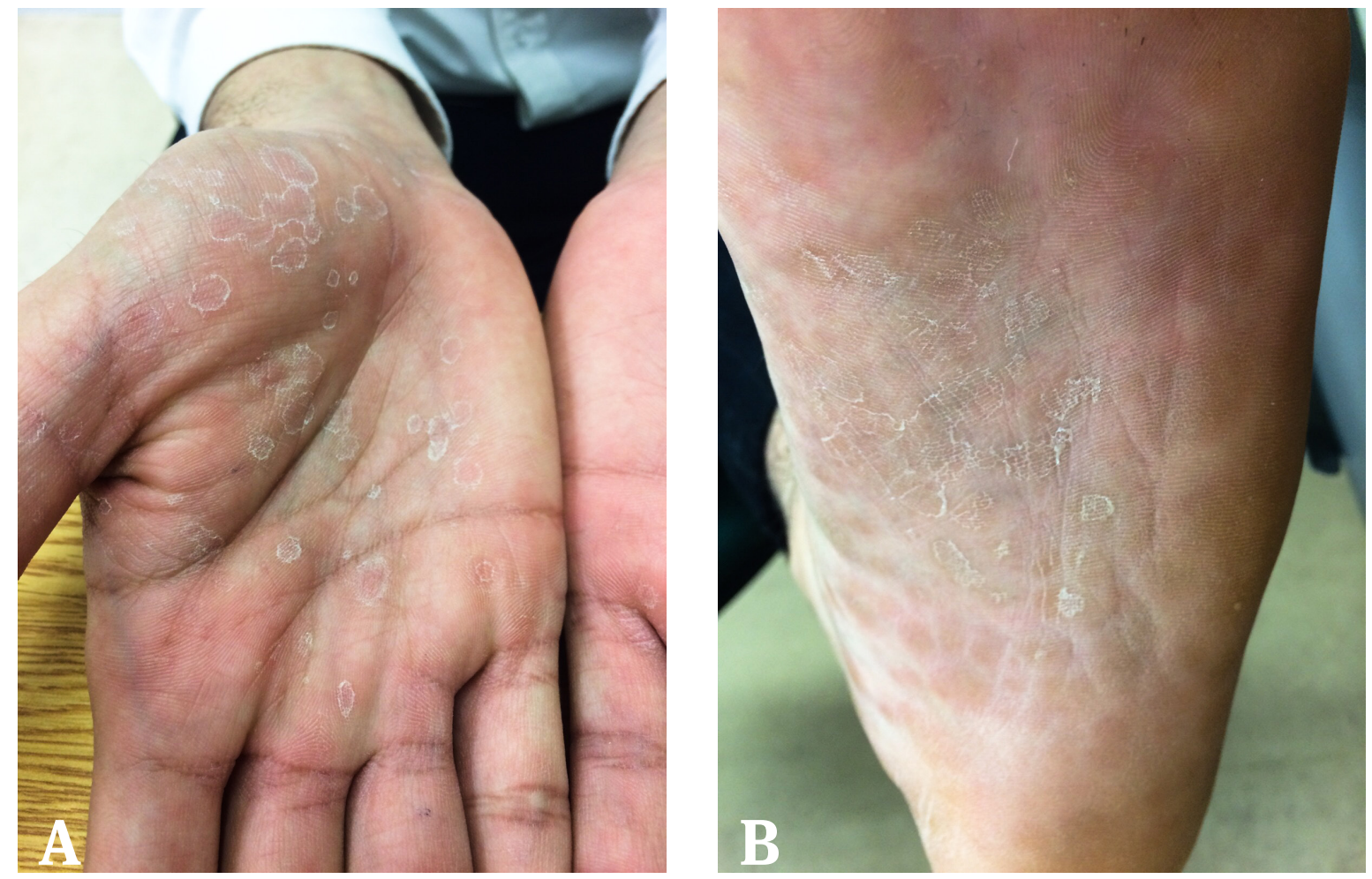

Figura 2. A y B) Placas en palmas y plantas con collaretes descamativos

como "chancro", típicamente aparece 2-4 semanas después del contacto inicial con la espiroqueta. Para este momento, los organismos se han diseminado desde el sitio primario de la infección hacia varios órganos y sistemas y a través de la dermis, iniciando el estado conocido como sífilis secundaria, esta etapa está caracterizada por hallazgos clínicos variados, incluyendo una amplia variedad de manifestaciones cutáneas (3), como también de signos y síntomas sistémicos que típicamente aparecen a las 4-10 semanas de la infección inicial.

Posteriormente se continua la etapa de sífilis latente, en la que el sistema inmune da lugar a una infección asintomática que puede durar varios años y el paciente puede tener episodios de espiroquetemia y manifestaciones clínicas, solo el $15-40 \%$ de los pacientes desarrollan una forma recrudescente de la enfermedad, la sífilis terciaria ${ }^{(1,4)}$.

Dentro de las manifestaciones clínicas más frecuentes de la sífilis secundaria se encuentra el típico exantema palmar y plantar que es la manifestación dermatológica más común, las lesiones plantares y palmares se encuentran rodeadas de hiperqueratosis y un anillo o collar delgado descamativo, más conocido como el collarete de Biett, otras manifestaciones incluyen: erupciones maculares y papulares pálidas, las cuales estan difusamente diseminadas en el tronco y extremidades superiores e inferiores, lesiones hipo o hiperpigmentadas, condiloma lato, alopecia característica en parches "apolillada", placas en la mucosa genital y/o mucosa oral, también comúnmente vistas en este estadio de la enfermedad ${ }^{(1,3,5)}$.

Adicionalmente, la lámina ungular y el tejido periungular pueden estar comprometidos. Las alteraciones en la lámina ungular incluye el desarrollo de surcos transversos, onicolisis y onicogrifosis. El compromiso del tejido periungular (paroniquia sifilítica) puede resultar en una induración violácea muy dolorosa, la cual raramente puede progresar a absceso ${ }^{(6)}$

El diagnostico de sífilis secundaria se basa en una historia médica compatible, la aparición de lesiones cutáneas o en mucosas, un RPR reactivo mayor o igual a 1:4 diluciones y un test treponémico confirmatorio positivo (Fluorescent Treponemal Antibody Absorption, FTA-abs) ${ }^{(1,4)}$.

La penicilina G parenteral ha sido usada desde 1940 
para el tratamiento de todos los estadios de la sífilis, el tratamiento recomendado por la OMS en adultos para sífilis primaria y secundaria es penicilina benzatinica G 2.4 millones de unidades intramuscular en dosis única (7), para sífilis latente temprana es penicilina benzatinica G 2.4 millones de unidades IM en dosis única, sífilis latente tardía o de duración desconocida es penicilina benzatinica $\mathrm{G} 2.4$ millones de unidades IM por 3 dosis semanales ${ }^{(7)}$.

Se debe monitorizar el progreso del tratamiento, la no disminución de los títulos de tests no treponémicos por un factor de 4 dentro de los 6 meses post-terapia, o la persistencia de signos y síntomas de la enfermedad, sugieren falla del tratamiento o reinfección.

Los pacientes deben ser reexaminados clínicamente y tener nuevas serología a los 6 y 12 meses del tratamiento. En casos sospechosos de falla al tratamiento o reinfección, se debe re-tratar y realizar nuevamente test para $\mathrm{VIH}^{(4)}$.

\section{CONCLUSIÓN}

Se describen 2 casos con las manifestaciones cutáneas más comunes de sífilis secundaria, pero que no son tan frecuentes en nuestro medio debido a la falta de atención médica oportuna en estadios tempranos de la enfermedad.

\section{REFERENCIAS}

1. Cruz AR, Pillay A, Zuluaga AV, Ramirez LG, Duque JE, Aristizabal GE, et al. Secondary Syphilis in Cali, Colombia: New Concepts in Disease Pathogenesis. PLoS Negl Trop Dis 2010, 4(5).

2. Newman L, Rowley J, Vander Hoorn S, Wijesooriya NS, Unemo M, Low N, et al. Global Estimates of the Prevalence and Incidence of Four Curable Sexually Transmitted Infections in 2012 Based on Systematic Review and Global Reporting. PLoS One. 2015 Dec 8;10(12).

3. Hernández ÓJ, Sarmiento K, Carrillo MA, Durán M, Augusto J, Costa D. Sífilis secundaria que simula una reacción leprosa de tipo 1 Resumen. Rev Asoc Colomb Dermatol. 2014;1:74-6.

4. Zeltser R, Kurban AK. Syphilis. Clin Dermatol. 2004 Nov-Dec;22(6):461-8.

5. Shockman S, Buescher LS, Stone SP. Syphilis in the United States. Clin Dermatol. 2014 MarApr;32(2):213-8

6. Balagula Y, Mattei PL, Wisco OJ, Erdag G, Chien AL. The great imitator revisited: the spectrum of atypical cutaneous manifestations of secondary syphilis. Int J Dermatol. 2014 Dec; 53(12):1434-41.

7. WHO Guidelines for the Treatment of Treponema pallidum (Syphilis). Geneva: World Health Organization; 2016. Citado 12 dic 2016. Disponible en: https://www.ncbi.nlm.nih.gov/books/ NBK384904/ 